\title{
An inducible transgenic mouse breast cancer model for the analysis of tumor antigen specific CD8 ${ }^{+} \mathrm{T}$-cell responses
}

\author{
Michael Bruns ${ }^{1}$, Jara Wanger ${ }^{1,4}$, Olaf Utermöhlen ${ }^{2}$, Wolfgang Deppert ${ }^{1,3}$ \\ ${ }^{1}$ Heinrich-Pette-Institute, Leibniz-Institute for Experimental Virology, Hamburg, Germany \\ ${ }^{2}$ Institute for Medical Microbiology, Immunology and Hygiene, Medical Center and Center for Molecular Medicine Cologne \\ (CMMC), University of Cologne, Cologne, Germany \\ ${ }^{3}$ Institute for Tumor Biology, University Medical Center Hamburg-Eppendorf (UKE), University of Hamburg, Hamburg, Germany \\ ${ }^{4}$ Present Address: Woldsenweg 7, 20249, Hamburg, Germany \\ Correspondence to: \\ Wolfgang Deppert, e-mail: w.deppert@uke.de \\ Keywords: transgenic breast cancer mouse model, SV40 T-antigen, LCMV NP-epitope, CTL response, differential immune \\ reactivity \\ Received: August 11, $2015 \quad$ Accepted: October 06, $2015 \quad$ Published: October 19, 2015
}

\section{ABSTRACT}

In Simian virus 40 (SV40) transgenic BALB/C WAP-T mice tumor development and progression is driven by SV40 tumor antigens encoded by inducible transgenes. WAP-T mice constitute a well characterized mouse model for breast cancer with strong similarities to the corresponding human disease. BALB/c mice mount only a weak cellular immune response against SV40 T-antigen (T-Ag). For studying tumor antigen specific $\mathrm{CD8}^{+} \mathrm{T}$-cell responses against transgene expressing cells, we created WAP-T ${ }_{\mathrm{NP}}$ mice, in which the transgene additionally codes for the $\mathrm{NP}_{118-126}$-epitope contained within the nucleoprotein of lymphocytic choriomeningitis virus (LCMV), the immune-dominant $T$-cell epitope in BALB/C mice. We then investigated in WAP-T ${ }_{\mathrm{NP}}$ mice the immune responses against SV40 tumor antigens and the NP-epitope within the chimeric T-Ag/ NP protein $\left(\mathrm{T}-\mathrm{Ag}_{\mathrm{NP}}\right)$. Analysis of the immune-reactivity against T-Ag in WAP-T and of $T-\mathrm{Ag}_{\mathrm{NP}}$ in WAP-T $\mathrm{NP}_{\mathrm{N}}$ mice revealed that, in contrast to wild type (wt) BALB/c mice, WAP-T and WAP-T ${ }_{N P}$ mice were non-reactive against T-Ag. However, like wtBALB/c mice, WAP-T

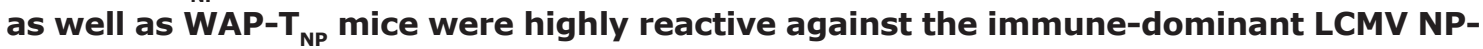
epitope, thereby allowing the analysis of NP-epitope specific cellular immune responses

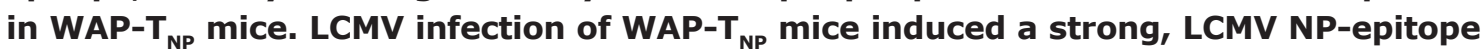
specific CD8 ${ }^{+} \mathrm{T}$-cell response, which was able to specifically eliminate $\mathrm{T}-\mathrm{Ag}_{\mathrm{NP}}$ expressing mammary epithelial cells both prior to tumor formation (i.e. in cells of lactating mammary glands), as well as in invasive tumors. Elimination of tumor cells, however, was only transient, even after repeated LCMV infections. Further studies showed that already non-infected WAP-T ${ }_{\text {NP }}$ tumor mice contained LCMV NP-epitope specific CD8+ T-cells, albeit with strongly reduced, though measurable activity. Functional impairment of these 'endogenous' NP-epitope specific T-cells seems to be caused by expression of the programmed death-1 protein (PD1), as anti-PD1 treatment of splenocytes from ${ }_{W A P-T_{N P}}$ tumor mice restored their activity. These characteristics are similar to those found in many tumor patients and render WAP-T $\mathrm{NP}_{\mathrm{NP}}$ mice a suitable model for analyzing parameters to overcome the blockade of immune checkpoints in tumor patients.

\section{INTRODUCTION}

Breast cancer is the leading cause of cancer deaths among women in industrialized countries and despite improved diagnostic and therapeutic options accounts for $23 \%$ of the total cancer cases and $14 \%$ of cancer deaths [1]. In order to achieve a reduction in breast cancer mortality, it thus is vital to improve breast cancer treatment, specifically treatments inhibiting metastatic spread of disseminated tumor cells. 
In addition to conventional treatments after surgical removal of the primary tumor, like chemo- and radiotherapy, immune-therapy might develop as a promising option. It thus is vital to understand the mechanisms of anti-tumor immune responses for a given tumor entity and the ensuing mechanisms of immune evasion.

For a detailed study of mammary carcinogenesis, and of immune reactions during early and late processes of tumor development and progression, we used the BALB/c mouse based WAP-T model, a well characterized immunecompetent mouse model for oncogene-induced mammary carcinogenesis. Upon induction of the whey acidic protein (WAP) promoter by lactotrophic hormones via mating, expression of SV40 T-antigens (T-Ag, small t, and 17kT antigens) drives transformation of mammary epithelial cells and ultimately tumor growth [2, 3]. Additional expression of mutant p53 in bi-transgenic WAP-T/WAPmutp53 bi-transgenic mice aggravates tumor progression, and enhances metastasis to the lungs $[3,4]$. The clinical relevance of the WAP-T mouse model is emphasized by comparison with human ductal carcinoma in situ [3, 5] and molecular similarities between invasive WAP-T and human triple-negative mammary carcinoma subtypes $[6,7]$. These carcinomas represent about $20 \%$ of all ductal mammary carcinomas and are characterized by bad prognosis.

$\mathrm{H}-2^{\mathrm{d}}$-restricted BALB/c mice are considered as "low responders" in terms of a specific $\mathrm{CD}^{+}$cytotoxic T lymphocyte (CTL) response towards SV40 T-Ag [8]. Nevertheless, protective cellular immunity against transplantable murine SV40 tumors can be achieved by pre-immunization with SV40 or purified T-Ag, which induces an efficient and long-lasting $\mathrm{CD}^{+}$helper T-cell dependent CTL response against established SV40 tumor cells (e.g. mKSA) [9, 10]. As the T-Ag specific CTL response in $\mathrm{BALB} / \mathrm{c}$ mice is weak, and as, furthermore, the major histocompatibility complex (MHC) class I H-2 ${ }^{\mathrm{d}}$ restricted T-Ag specific T-cell epitopes have not yet been characterized, the analysis of T-Ag specific $\mathrm{CD}^{+} \mathrm{T}$-cell responses in BALB/c mice is technically difficult. To allow the epitope-specific analysis of a well-defined $\mathrm{CD}^{+}$ $\mathrm{T}$-cell response against a tumor antigen in WAP-T mice, we inserted the coding sequence (a 33 bp oligomer) for

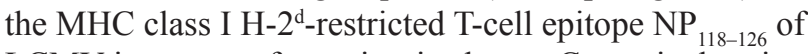
LCMV into a transformation-irrelevant $\mathrm{C}$-terminal region of T-Ag, to obtain WAP-T ${ }_{\mathrm{NP}}$ mice (Fig. 1A, a detailed description of the WAP-T/WAP- $\mathrm{T}_{\mathrm{NP}}$ mice used in this

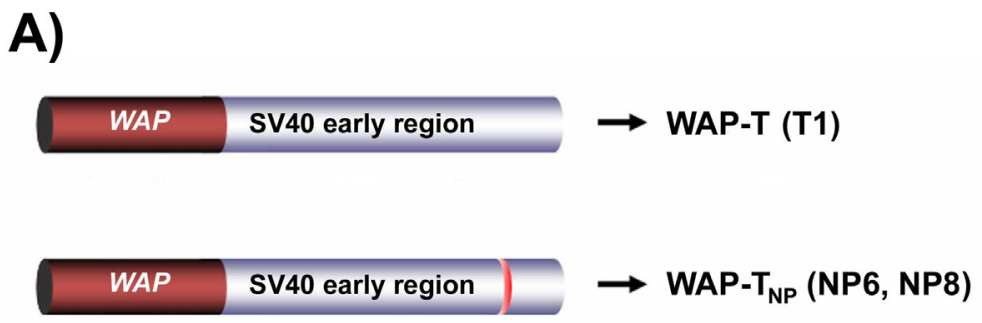

B)

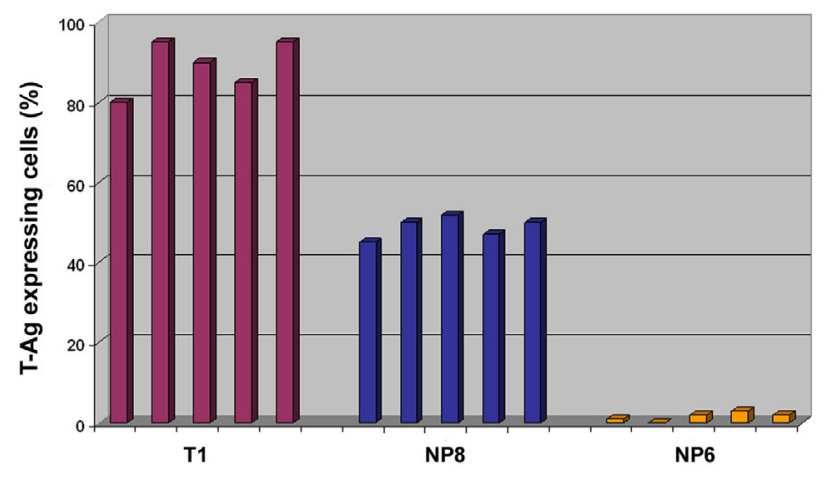

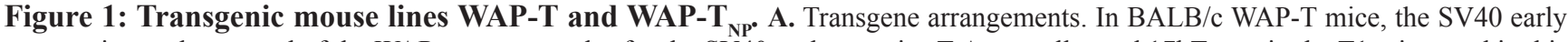
gene region under control of the WAP promoter codes for the SV40 early proteins T-Ag, small t, and 17kT, e.g. in the T1 mice used in this study (above). WAP- $\mathrm{T}_{\mathrm{NP}}$ mice, in addition, code for the strong MHC class I H2 ${ }^{\mathrm{d}}$ restricted LCMV T-cell epitope $\mathrm{NP}_{118-126}$, inserted as a 33 bp oligonucleotide into a transformation-irrelevant carboxy-terminal region of T-Ag (for details see Schulze-Garg et al. [5]); NP6 and NP8 mice were selected for further studies (see Materials and methods). B. Distribution of T-Ag expressing cells in lactating mammary glands of T1, NP8, and NP6 mice (immune histology) The percentage of T-Ag positive cells detected in lactating mammary glands (7 days pp) of five individual T1, NP8, and NP6 mice each was evaluated. 
study is given in Materials and Methods.) [2]. The H-2drestricted LCMV NP-epitope is dominant in BALB/c mice, as recognition of this motif by specific CTLs leads to virus clearance within 14 days after infection [11]. We previously had shown that immunization of mice with chimeric recombinant $\mathrm{T}-\mathrm{Ag}$ proteins carrying this epitope induces a strong CTL response [12]. Expression of the chimeric $T-A g-N P$ gene thus should allow the NP-epitope specific analysis of the $\mathrm{CD} 8^{+} \mathrm{T}$-cell immune response against the $\mathrm{T}-\mathrm{Ag}_{\mathrm{NP}}$ tumor antigen after $\mathrm{LCMV}$ infection, if WAP- $\mathrm{T}_{\mathrm{NP}}$ mice are able to mount a cellular immune response against this epitope. As the immune reactions in LCMV infected $\mathrm{BALB} / \mathrm{c}$ mice are very well characterized [13], comparative analyses of LCMV infected BALB/c and of WAP-T ${ }_{\mathrm{NP}}$ tumor mice should provide additional tools for the characterization of NP-epitope specific immune reactions in $\mathrm{WAP}-\mathrm{T}_{\mathrm{NP}}$ mice at different stages of tumor development and progression. Likewise, comparison of immune reactions in WAP- $\mathrm{T}_{\mathrm{NP}}$ mice, presenting the NP-epitope, and in WAP-T mice, not presenting the NP-epitope, further enhance the NP-epitope specificity of the WAP- $\mathrm{T}_{\mathrm{NP}}$ model for the analysis of an NP-epitope specific CTL response.

We here report that in contrast to $\mathrm{wtBALB} / \mathrm{c}$ mice, WAP-T and WAP-T ${ }_{\mathrm{NP}}$ mice are immunologically nonreactive against SV40 T-Ag, but, like wtBALB/c mice, are highly reactive against LCMV. Infection of WAP$\mathrm{T}_{\mathrm{NP}}$ mice with LCMV leads to elimination of $\mathrm{T}-\mathrm{Ag}_{\mathrm{NP}}$ expressing cells, both prior to tumor formation as well as in invasive tumors. As the immune-dominant LCMV NP-epitope in $\mathrm{T}-\mathrm{Ag}_{\mathrm{NP}}$ is the only LCMV derived T-cell epitope in NP8 mice, elimination of $\mathrm{T}-\mathrm{Ag}_{\mathrm{NP}}$ expressing cells is NP-epitope specific. Elimination of tumor cells, however, is only transient. Interestingly, even without LCMV infection, tumor-bearing WAP- $\mathrm{T}_{\mathrm{NP}}$ mice contain LCMV NP-epitope specific $\mathrm{CD}^{+}$T-cells with low, but measurable CTL activity. CTL activity of these T-cells could be at least partially restored by anti-PD1 treatment, indicating that the endogenous cellular anti-tumor response gets compromised by expression of PD1 and/or PD-L1.

\section{RESULTS}

\section{NP8 mice are non-reactive against SV40 T-Ag, but highly reactive against the immune- dominant LCMV NP-epitope}

Transgenic expression of T-Ag in $\mathrm{T} 1$ or of $\mathrm{T}-\mathrm{Ag}_{\mathrm{NP}}$ in NP8 mice (see Fig. 1) could have various immunologic outcomes, e.g. induction of antigen-specific tolerance, ignorance of the antigen, or activation of a specific immune response. First, the immune-reactivity of T1 and NP8 mice against T-Ag was characterized by immunizing mice with infectious SV40 and compared to that of
wtBALB/c mice, followed by challenge with mKSA SV40 tumor cells (see scheme in Fig. 2A).

After injection of $10^{6} \mathrm{mKSA}$ cells, i.e. the ten-thousand-fold dose of tumor cells lethal for $50 \%$ of the mice [10], all naïve wtBALB/c mice (13/13 mice) succumbed to mKSA tumors within a mean survival time of 21 days (Table I). Immunization by two sc injections of SV40 established long-term protection against mKSA tumors in almost all (12/13 mice) wt mice.

Remarkably, despite immunization with SV40 all of the T1 (6 of 6; mean survival time 18 days), and all of the NP8 mice (11 of 11, mean survival time 20 days) succumbed to mKSA tumors as rapidly as naïve wtBALB/c mice (Table I).

Murine cells are not permissive for infection with SV40, allowing only abortive infection during which relatively low amounts of T-Ag are expressed. Furthermore, this abortive infection should induce only a weak inflammatory response $[8,14]$. Thus, the lack of protection of T1 and NP8 mice against mKSA tumor cells could be due to the poor immunogenicity of SV40 in these mice. To test this possibility, in a repeat experiment a vaccinia virus (VV) recombinant encoding SV40 T-Ag (VV-941T) was used as a potent replicative immunogen. As expected, wt mice immunized with VV-941T were similarly protected (4/5 mice) against challenge inoculation of mKSA tumor cells (Fig. 2B). In contrast, similar to immunization with SV40, immunization with VV-941T did not protect NP8 mice. Four of five immunized mice succumbed to mKSA cells almost as rapidly as non-immunized mice (Fig. 2B). The lack of protection shows that even immunization with highly immunogenic VV-941T cannot induce T-Ag specific protective immunity in NP8 mice, indicating that transgenic expression of weakly immunogenic T-Ag interferes with induction of T-Ag specific CTLs.

In contrast to the weakly immunogenic $\mathrm{H}-2^{\mathrm{d}}$ restricted epitopes of T-Ag, the LCMV-derived $\mathrm{H}-2^{\mathrm{d}}-$ restricted, immune-dominant epitope $\mathrm{NP}_{118-126}$ is highly immunogenic [13]. The responsiveness of NP8 mice against this epitope, endogenously expressed within the transgenic $\mathrm{T}-\mathrm{Ag}_{\mathrm{NP}}$, was determined in mice acutely infected with LCMV (Fig. 3). The effect of transgene expression was assessed in induced NP8 mice containing intraepithelial neoplasia (MIN) and expressing large amounts of T-Ag, while effects of any spontaneous transgene expression were assessed in virgin NP8 mice. As positive controls, wt and T1 mice, both devoid of endogenous expression of the $\mathrm{NP}_{118-126}$ epitope, were used.

By day 8 post infection, i.e. at the peak of the LCMV-specific immune response [15], the typical expansion of total $\mathrm{CD}^{+}$spleen cells was observed in spleens of wt, T1, non-induced NP8, as well as of MIN containing NP8 mice to similar degrees (Fig. 3A, left). Moreover, among the total $\mathrm{CD} 8^{+}$spleen cells the frequencies of $\mathrm{NP}_{118-126}$-specific $\mathrm{CD} 8^{+}$cells were similarly 
A)

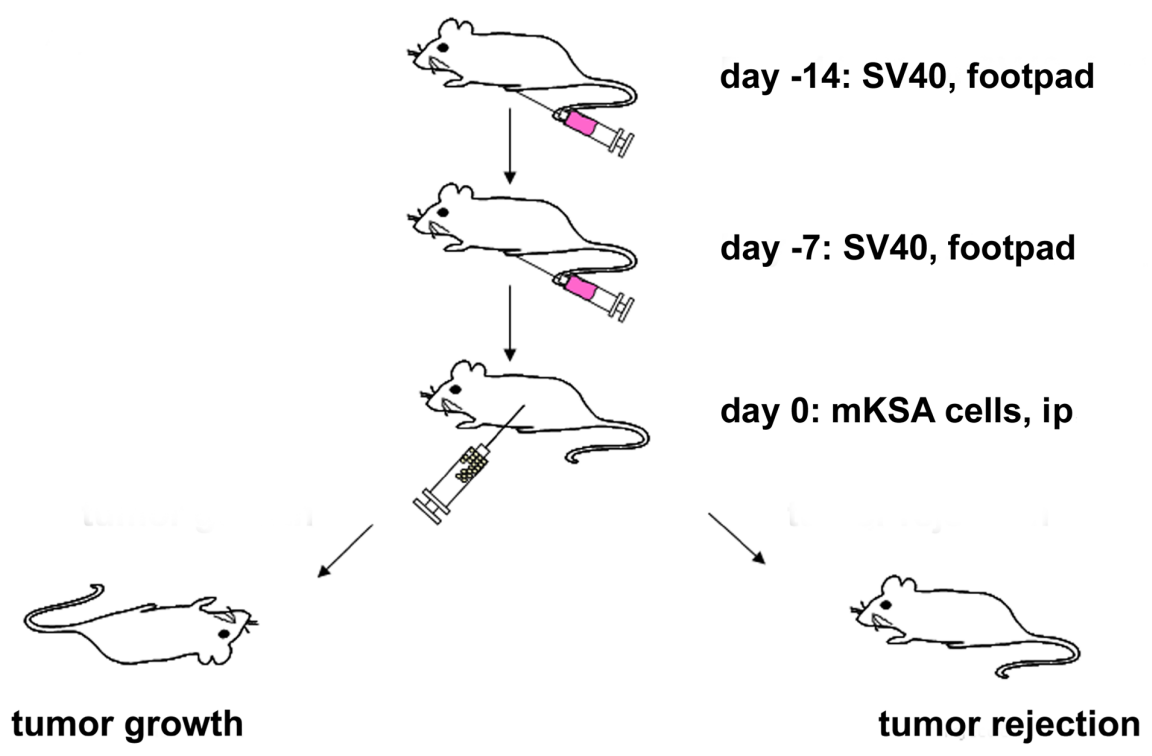

B)

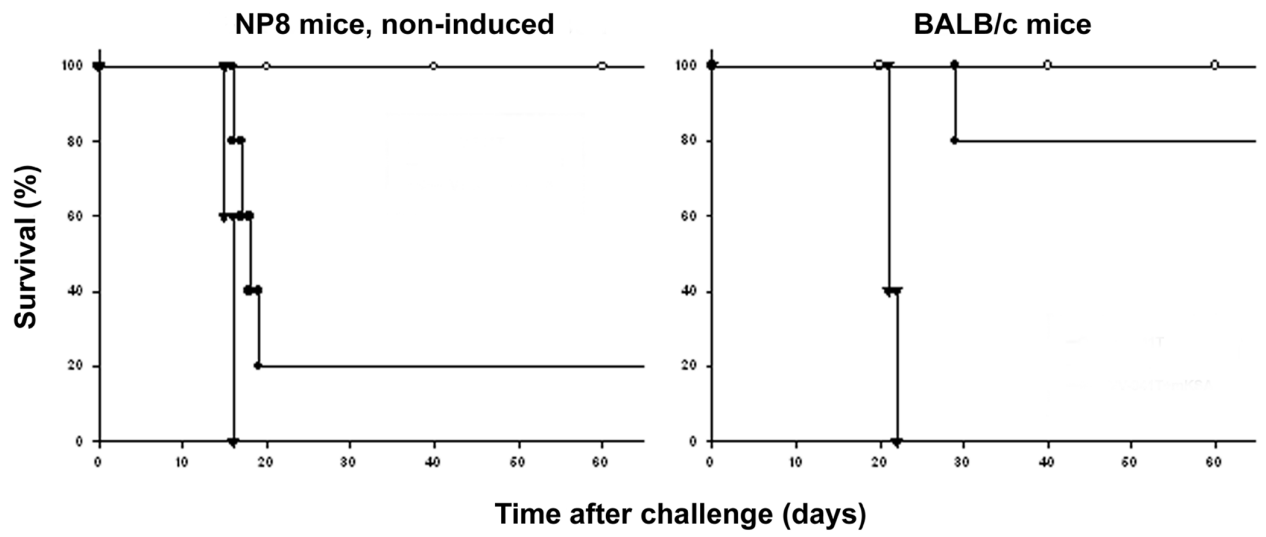

Figure 2: Impaired immune reaction against SV40 T-Ag in NP8 mice. A. Immunization protocol for SV40 (red syringe) and mKSA tumor cells (clear syringe) in the "mKSA tolerance test". Mice mounting an immune response against T-Ag are protected against transplanted mKSA cells ("tumor rejection"), while mice with an impaired immune response die from tumor growth. B. In contrast to $\mathrm{BALB} / \mathrm{c}$ mice, naïve (e.g. non-induced) NP8 mice succumb to tumor growth as a consequence of a reduced immune reaction against T-Ag presenting mKSA cells. Five mice per group $(n=5)$ were either infected with $10^{5}$ PFU VV-941T only $(\circ)$, treated with $10^{5}$ mKSA cells only $(\boldsymbol{\nabla})$, or a combination of $10^{5} \mathrm{PFU}$ of VV-941T and $10^{5} \mathrm{mKSA}$ cells was applied $(\bullet)$; total observation time was 60 days.

Table 1: Despite prior immunization with SV40, WAP-T and WAP-T ${ }_{\mathrm{NP}}$ mice succumb to challenge with SV40 T-Ag expressing mKSA tumor cells as rapidly as naïve wt mice

\begin{tabular}{lcc}
\hline Mice & Tumor incidence $^{\mathbf{a}}$ & Mean survival time (days) $^{\text {w }}$ \\
\hline wt, naïve & $13 / 13$ & 21 \\
wt, T-Ag immunized & $1 / 13$ & $>100$ \\
T1, T-Ag immunized & $6 / 6$ & 18 \\
NP8, T-Ag immunized & $11 / 11$ & 20 \\
\hline
\end{tabular}

${ }^{a}$ T1 or NP8 mice or wtBALB/c mice of both genders were immunized by subcutaneous (sc) injection with $5 \times 10^{6}$ plaqueforming units (PFU) of SV40 on days -14 and -7 before intra-peritoneal (ip) challenge with $10^{6} \mathrm{mKSA}$ tumor cells. Growth of tumors and survival of mice were monitored up to day 100 post challenge. 
elevated in wt, T1, non-induced NP8, or lactation-induced NP8 mice (Fig. 3A, right).

The LCMV-specific effector function of these splenic cells was determined in cytotoxicity assays against BALB/c fibroblast either infected with LCMV or loaded with graded concentrations of synthetic peptides representing the epitope $\mathrm{NP}_{118-126}$ (Fig. 3B). Furthermore, crude spleen cell populations of T1, non-induced NP8, or NP8 mice 4 months after involution (i.e. NP8 mice containing MIN) exerted similar cytotoxic activity against
LCMV-infected SV40 transformed BALB/c (BALB-SV) fibroblasts (Fig. 3B). Splenocytes from infected T1 or noninduced NP8 mice lysed BALB-SV target cells loaded with graded concentrations of the synthetic $\mathrm{NP}_{118-126}$ peptide to similar extents. In comparison to splenocytes from T1 or non-induced NP8 mice, splenocytes from induced NP8 mice lysed target cells loaded with high concentrations $\left(10^{-6}\right.$ and $\left.10^{-8} \mathrm{M}\right)$ of synthetic $\mathrm{NP}_{118-126}$ peptide slightly less effective, but this difference was not statistically significant.

A)
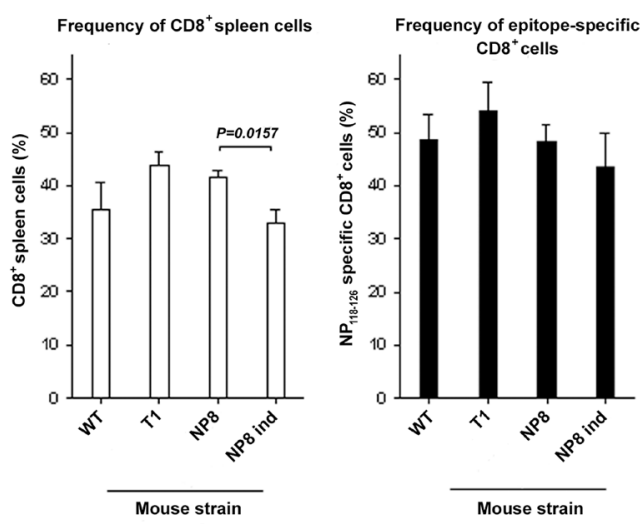

B) Effector cells prepared from mouse strain:
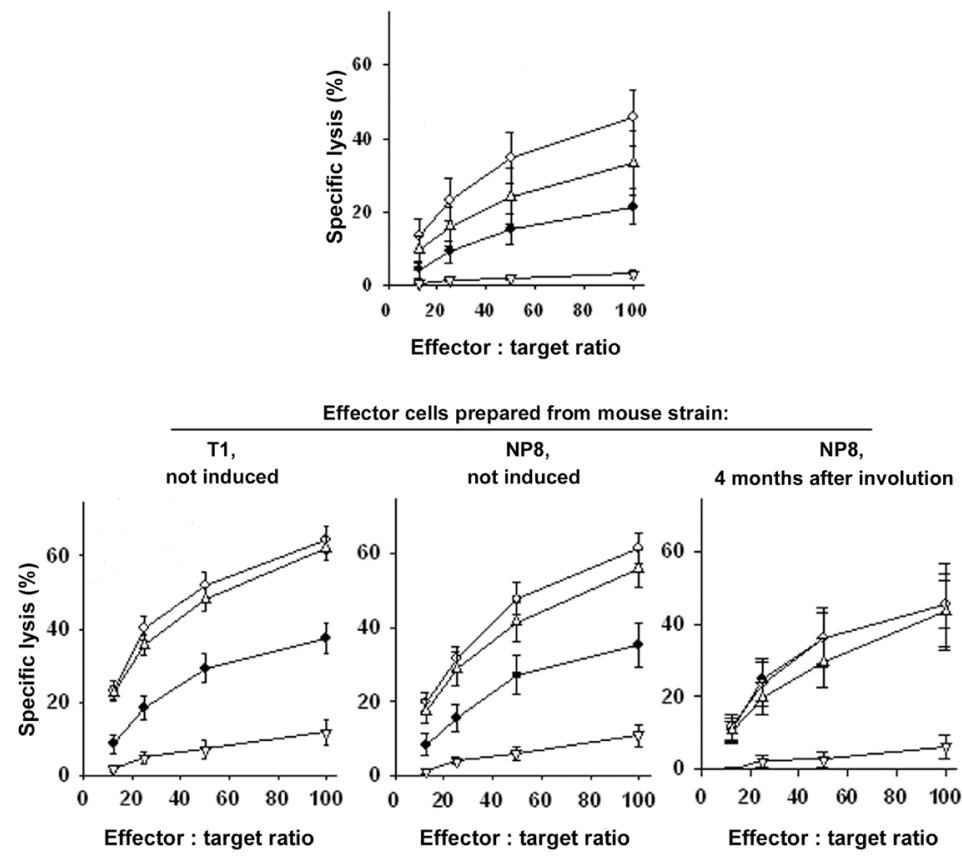

Figure 3: Frequency and functionality of $\mathrm{CD8}^{+} \mathrm{T}$ cells in $\mathrm{T} 1$ and NP8 mice after acute systemic infection with LCMV. Groups of wt, non-induced (naïve) T1 and NP8, or induced NP8 mice (MIN) were infected intravenously (iv) with $10^{5}$ PFU of LCMV. On day 8 after infection splenic single cell suspensions were prepared. A. The frequency of CD8 ${ }^{+}$(left) and of $\mathrm{NP}_{118-126^{-}} \mathrm{specific}$ $\mathrm{CD}^{+}$spleen cells (right) was determined by flow cytometry using CD8-specific mAb and H-2 Ld pentamers loaded with the NP${ }_{118-126}$ epitope. B. LCMV-specific cytotoxic activity of crude spleen cell suspensions was determined in 4 h chromium-release assays. Syngeneic $\mathrm{BALB} / \mathrm{c}-\mathrm{SV}$ fibroblasts were either infected $48 \mathrm{~h}$ prior to the assay with LCMV at multiplicity of infection 0.01 ( $\downarrow)$ or loaded with $10^{-6}(\diamond), 10^{-8}(\Delta)$, or $10^{-10} \mathrm{M}(\nabla)$ of the synthetic peptide epitope $\mathrm{NP}_{118-126}$, respectively. Shown are cumulative data from three independent experiments (numbers of mice per genotype: wt $n=8$, T1 $n=7$, NP8 $n=6$, induced NP8 $n=3$ ). 
The data show that in response to systemic infection with LCMV non-induced as well as induced NP8 mice effectively generate specific $\mathrm{CD}^{+} \mathrm{T}$ cells against the highly immunogenic, immune-dominant $\mathrm{NP}_{118-126}$ epitope with similar frequencies and cytotoxic activities as $\mathrm{T} 1$ and $w t B A L B / c$ mice. In contrast, even immunization with a highly immunogenic T-Ag-expressing recombinant $\mathrm{VV}$ induced protective immunity against T-Ag-expressing tumors only in wtBALB/c mice, but not in T-Ag-transgenic WAP-T and WAP- $\mathrm{T}_{\mathrm{NP}}$ mice. This suggests that in $\mathrm{WAP}-\mathrm{T}_{\mathrm{NP}}$ mice transgenic expression of weakly immunogenic, T-Ag-derived epitopes interferes with the induction of T-Ag specific CTLs, possibly by inducing a state of hypo- or non-responsiveness, while presentation of the highly immunogenic $\mathrm{NP}_{118-126}$ epitope does not induce such a state. Although the reasons for this differential responsiveness to MHC class-I-restricted epitopes encoded by the same transgene are unknown to us, the strong reactivity against the NP-epitope provided us with a tool to analyze tumor-antigen specific immune responses in $\mathrm{WAP}_{\mathrm{NP}}$ mice.

\section{LCMV infection induces NP-epitope specific immune responses against $\mathrm{T}-\mathrm{Ag}_{\mathrm{NP}}$ expressing cells in NP8 mice}

\section{LCMV infection leads to elimination of $\mathbf{T}-\mathrm{Ag}_{\mathrm{NP}}$ expressing cells in lactating NP8 mice}

We next asked, whether the vigorous LCMV NP-specific $\mathrm{CD}^{+}$T-cell response seen after LCMV infection of NP8 mice could eliminate endogenous T- $\mathrm{Ag}_{\mathrm{NP}}$ expressing mammary epithelial cells. As the immune response against tumor cells often is compromised, we, for initial experiments, used NP8 mice in which expression of the chimeric $T-A g / N P$ transgene was induced by lactation, i.e. at a time where $\mathrm{T}-\mathrm{Ag}_{\mathrm{NP}}$ expressing cells are still normal in function. Maximal expression of T-Ag in mammary gland cells is observed between days 5-10 postpartum (pp) (Fig. 4A). After acute infection with LCMV, mature, antiviral $\mathrm{CD}^{+}$effector cells can be detected between days 6-12 post infection (pi). Accordingly, we infected maternal NP8 mice shortly after delivery and examined their mammary glands for $\mathrm{T}-\mathrm{Ag}_{\mathrm{NP}}$ expression on day $7 \mathrm{pp}$ (Fig. 4B). Since the infectious dose of LCMV affects the strength of the ensuing immune response [11], we infected different groups of mice with ten-fold escalating doses of LCMV ranging from $10^{3}$ to $10^{6} \mathrm{PFU}$.

In mice infected with either $10^{5}$ or $10^{6} \mathrm{PFU}$ of LCMV, virtually no $\mathrm{T}-\mathrm{Ag}_{\mathrm{NP}}$ expressing cells were detectable any more. On the other side, inflammatory reactions, as indicated in Fig. 4B by the altered histology of the mammary glands of mice infected with $10^{5}$ or $10^{6}$ PFU of LCMV, could be detected, reflecting a wide-spread LCMV infection [16]. To exclude that elimination of $\mathrm{T}-\mathrm{Ag}_{\mathrm{NP}}$ expressing cells was due to some unspecific effects of inflammation during viral infection rather than to a specific immune response against the immune-dominant LCMV epitope $\mathrm{NP}_{118-126}$, additional groups of mice were infected with $\mathrm{VV}$ recombinants encoding either the LCMV glycoprotein precursor (VV-G2) or the LCMV nucleoprotein (VV-YN4) (Fig. 4C) [13]. Similar to infection with LCMV (Fig. 4C, right), after infection with VV-YN4 only few remaining $\mathrm{T}-\mathrm{Ag}_{\mathrm{NP}}$ expressing cells were detectable (Fig. 4C, left). In contrast, infection with VV-G2, encoding the LCMV glycoprotein precursor, did not lead to a reduction of $\mathrm{T}-\mathrm{Ag}_{\mathrm{NP}}$ positive cells (Fig. $4 \mathrm{C}$, middle). The specificity for NP-epitope specific elimination of $\mathrm{T}-\mathrm{Ag}_{\mathrm{NP}}$ expressing cells was further confirmed by additionally infecting the mice with VV virus recombinant VV-941T encoding the SV40 T-Ag (Supplementary Fig. 1). As expected from the data shown in Figs. 2 and 3, VV-941T was not able to induce elimination of $\mathrm{T}-\mathrm{Ag}_{\mathrm{NP}}$ expressing cells.

The data show that infection with either LCMV or VV-YN4, both expressing the LCMV nucleoprotein, specifically leads to NP-epitope specific elimination of $\mathrm{T}-\mathrm{Ag}_{\mathrm{NP}}$ expressing cells due to induction of an NP-epitope specific T-cell response that eliminates $\mathrm{T}-\mathrm{Ag}_{\mathrm{NP}}$ expressing cells.

Adoptive transfer of LCMV NP-specific splenocytes into lactating NP8 mice leads to selectivse elimination of $\mathbf{T}-\mathrm{Ag}_{\mathrm{NP}}$ expressing mammary epithelial cells

To provide stringent evidence that elimination of $\mathrm{T}-\mathrm{Ag}_{\mathrm{NP}}$ expressing cells is due to the activity of immune cells rather than to some unspecific inflammatory response of the host, we performed adoptive transfers of fully active effector cells from acutely LCMV-infected wtBALB/c into lactating recipient NP8 mice. Spleen cells from donor mice infected 7 days earlier were adoptively transferred into NP8 mice at day 5 pp (Fig. 5A). Eight days after transfer, mammary glands of recipients of spleen cells from LCMV infected donors (Fig. 5B, panel a) showed a strong reduction in the number of $\mathrm{T}-\mathrm{Ag}_{\mathrm{NP}}$ expressing cells as compared to non-transferred controls (Fig. 5B, panel b). Specificity of this effect for the LCMV NP as immunogen was proven by a similarly quantitative reduction of $\mathrm{T}-\mathrm{Ag}_{\mathrm{NP}}$-expressing cells after transfer of spleen cells from donor mice infected with VV-NY4 (Fig. 5B, panel c), while transfer of spleen cells from donors infected with VV-941T did not conspicuously reduce the density of Tag-expressing cells (Fig. 5B, panel d).

Altogether the data show that specific immune responses against the LCMV NP-derived, immune-dominant epitope $\mathrm{NP}_{118-126}$ lead to a strong reduction of $\mathrm{T}-\mathrm{Ag}_{\mathrm{NP}}$ expressing mammary gland cells in lactating NP8 mice.

\section{LCMV infection leads to elimination of $\mathbf{T}-\mathbf{A g}_{\mathrm{NP}}$ expressing tumor cells in NP8 mice}

In the previous experiments the specific immune response was initiated during development and expansion of pre-cancerous mammary epithelial cells. Next we 


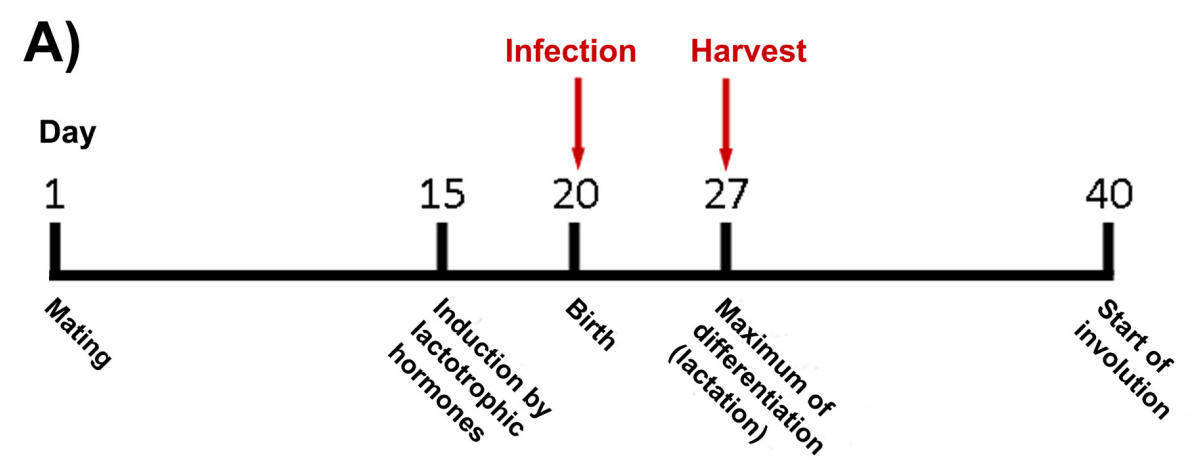

\section{B)}
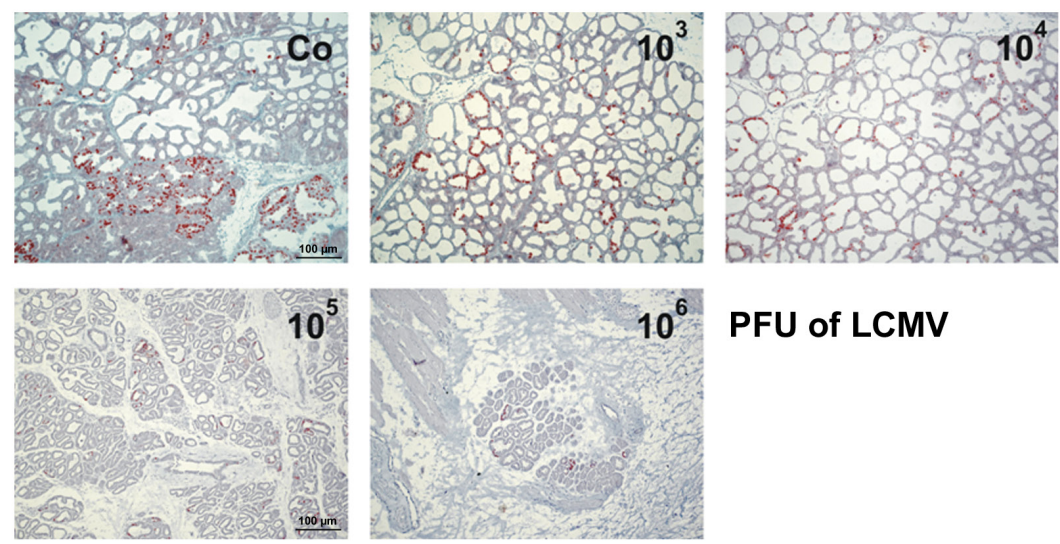

\section{PFU of LCMV}

\section{C)}
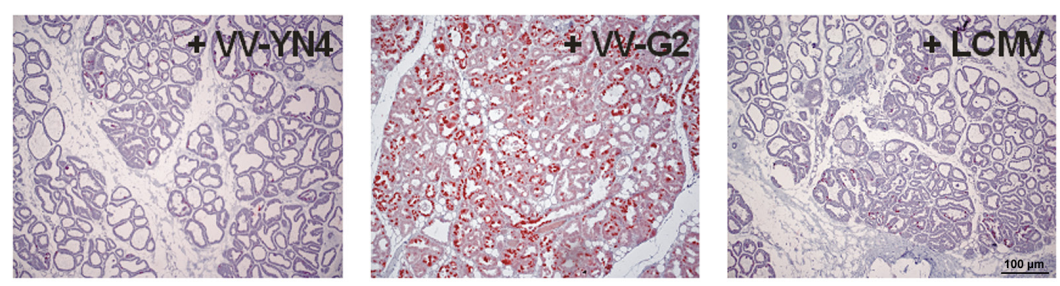

Figure 4: Infection of lactating NP8 mice with LCMV and VV recombinants for the analysis of a specific immune reaction against the $\mathbf{L C M V ~ N P _ { 1 1 8 - 1 2 6 }}$-epitope in $\mathbf{T}-\mathbf{A g}_{\mathrm{NP}}$. $\mathbf{A}$. Time line for harvesting the mammary glands after infection; four mice per group were infected with either different titers of LCMV or with $10^{5} \mathrm{PFU}$ of LCMV or VV recombinants - the relative amounts of T-Ag expressing cells are given as percentage in brackets. B. Immune-histological analysis for T-Ag expression of lactating mammary glands after infection with $10^{3}[40-60 \%], 10^{4}[10-20 \%], 10^{5}[2-6 \%]$, or $10^{6} \mathrm{PFU}$ of LCMV [2-6\%]; the preparation shown in the left upper corner presents an uninfected control tissue (Co) [100\%]. C. Infection of transgenic mice with $10^{5} \mathrm{PFU}$ of VV recombinants containing either the NP (VV-YN4, left) [2-4\%] or the glycoprotein-precursor of LCMV (VV-G2, middle) [ 100\%]. As control, NP8 mice were infected with LCMV (right) [2-6\%].

assessed, whether LCMV-infection could also induce a specific immune response in $\mathrm{T}-\mathrm{Ag}_{\mathrm{NP}}$ expressing tumors of NP8 mice. T-Ag expressing tumors in T1 mice served as control. T1 and NP8 tumor mice (tumor diameter about $1 \mathrm{~cm})$, respectively, were systemically infected with LCMV and tumors analyzed at days $0,3,5,7$, and 21 pi (Fig. 6). At day 0 of infection, in tumors of both, NP8 and $\mathrm{T} 1 \mathrm{mice}$, large areas of densely packed T-Ag expressing cells were observed. In T1 control mice, the pattern of T-Ag positive cells within the tumors remained almost unaffected up to day $21 \mathrm{pi}$. The somewhat disorganized histology of the mammary gland in LCMV infected T1 mice at day 7 most likely reflects inflammatory reactions induced by LCMV infection. In contrast, as early as day $3 \mathrm{pi}$, the density of $\mathrm{T}-\mathrm{Ag}_{\mathrm{NP}}$ positive cells was already slightly decreased in tumors of NP8 mice, 


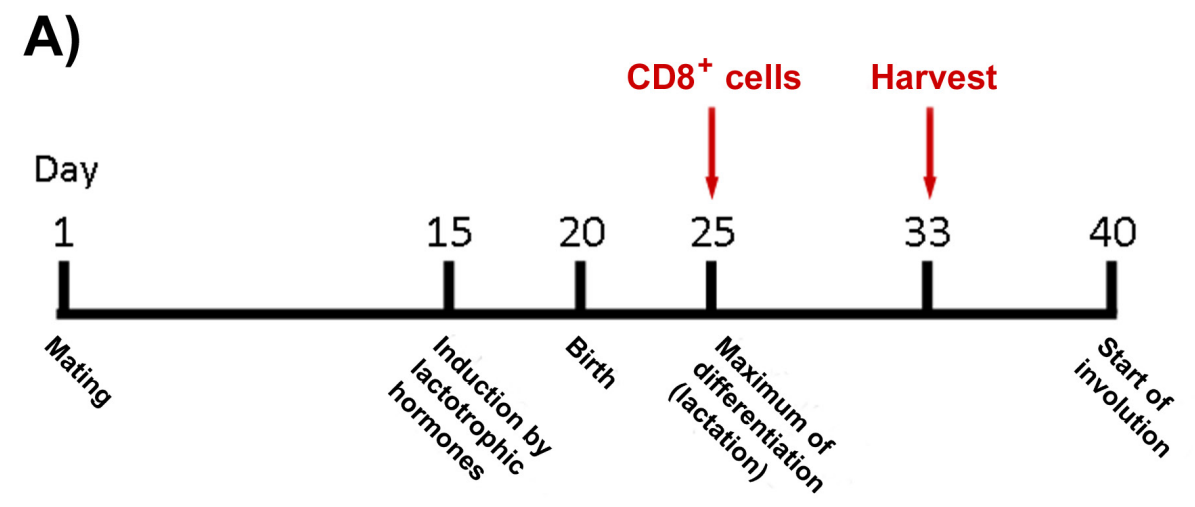

B)
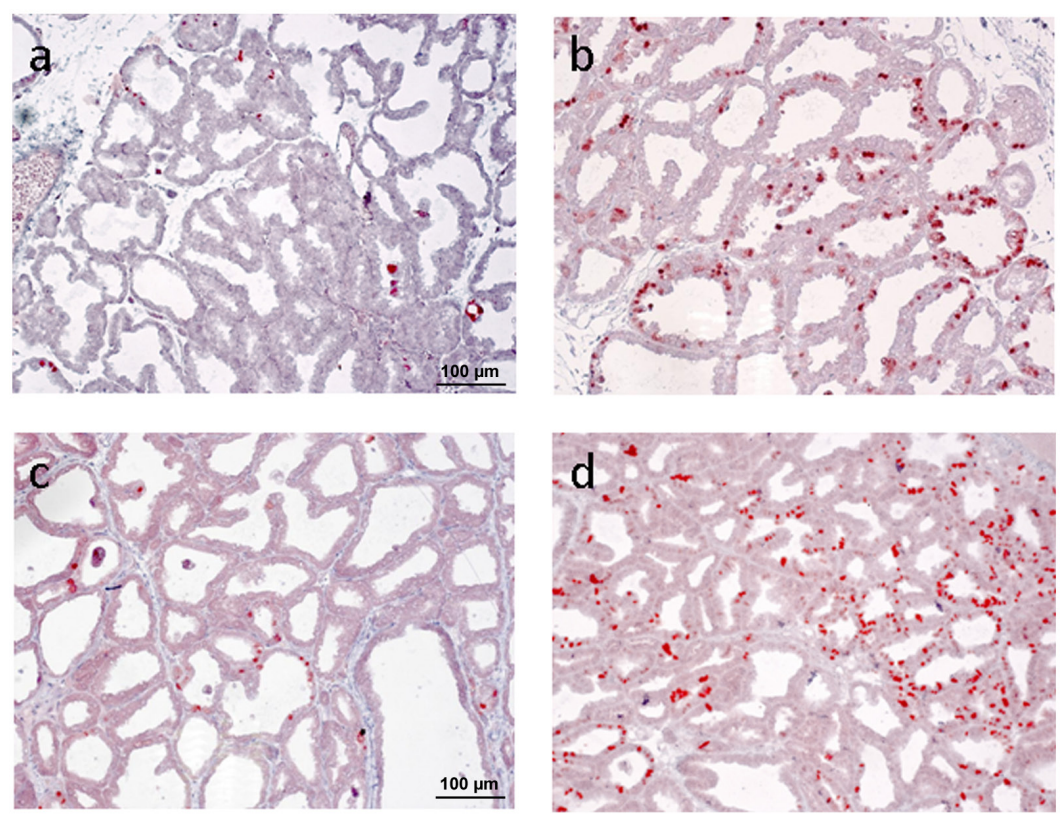

Figure 5: Adoptive transfer of immune cells from infected and uninfected BALB/c into NP8 mice. A. Scheme depicting the time point of splenocyte transfer from five individually infected BALB/c mice into the corresponding number of transgenic mice and harvest of their mammary glands; the calculated relative amounts of T-Ag positive cells are shown as percentage in brackets. B. NP8 mice received either the spleen cells of BALB/c mice infected with the VV recombinants containing the NP of LCMV (VV-YN4, c) [2-4\%] or the T-Ag of SV40 (VV-941T, d) [ 100\%]; mammary glands of NP8 mice, which received spleen cells from LCMV-infected BALB/c mice (LCMV, a) $[2-6 \%]$ or none $(\mathrm{Co}, \mathrm{b})[100 \%]$ served as positive and negative controls.

and from day 5 to 21 pi only individual $\mathrm{T}-\mathrm{Ag}_{\mathrm{NP}}$ positive cells, scattered within the tumor mass, were detected (Figs. 6A, 6B). For a better evaluation, tissue sections of T1 and NP8 tumor mice were compared at day $21 \mathrm{pi}$ with different magnifications, where the right panels represent the magnification applied in Fig. 6A (and in all other Figs), whereas, for a better overview, the panels in the middle show a 2.5 -fold and the panels on the left side a 5-fold lower magnification (Fig. 6B). Semi-quantitative evaluation of T-Ag positive cells in Fig. 6A (i.e. relative numbers of T-Ag expressing cells per section, for details see legend to Figs 4 and 5) graphically shows a rapid decline after LCMV infection in tumors of NP8 mice, while the fraction of T-Ag positive cells in tumors of T1 mice stayed relatively constant (Fig. 6C). Elimination of $\mathrm{T}-\mathrm{Ag}_{\mathrm{NP}}$ expressing cells in NP8 tumors after systemic infection with LCMV was additionally quantified in a subsequent experiment at day 7 pi by Western blot (Fig. 7A) and ELISA of tumor lysates (Fig. 7B) for T-Ag and revealed a strong reduction, while T-Ag levels in T1 tumors remained unaffected (Fig. 7B).

These data show that an effective LCMV NP-epitope specific T-cell response can also be induced in tumor-bearing NP8 mice. However, reduction of $\mathrm{T}-\mathrm{Ag}_{\mathrm{NP}}$ expressing tumor cells was transient. Despite the initially almost quantitative elimination of tumor cells in NP8 mice after LCMV infection, tumors reappeared about 6 weeks after treatment (Fig. 6C, 42 days). Transient reduction of $\mathrm{T}-\mathrm{Ag}_{\mathrm{NP}}$ expressing 
A)

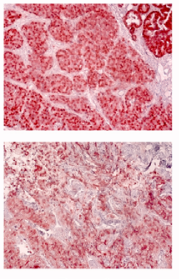

Day 0

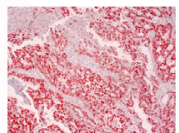

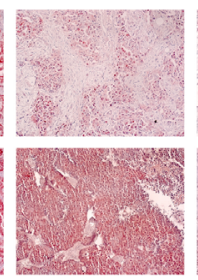

Day 5

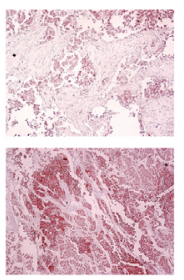

Day 7

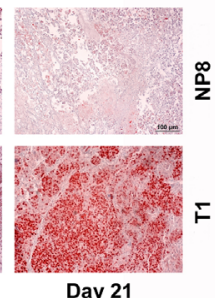

Day 21

B)

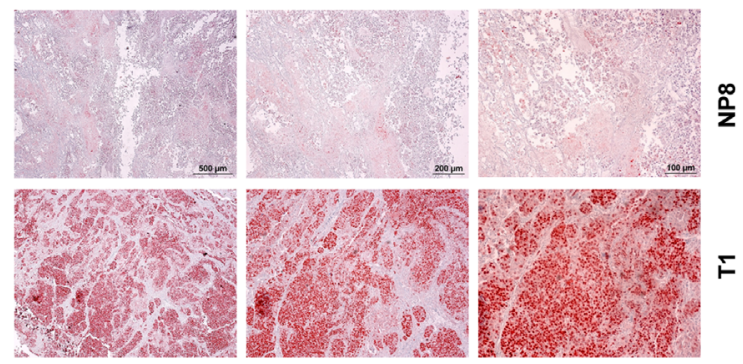

C)

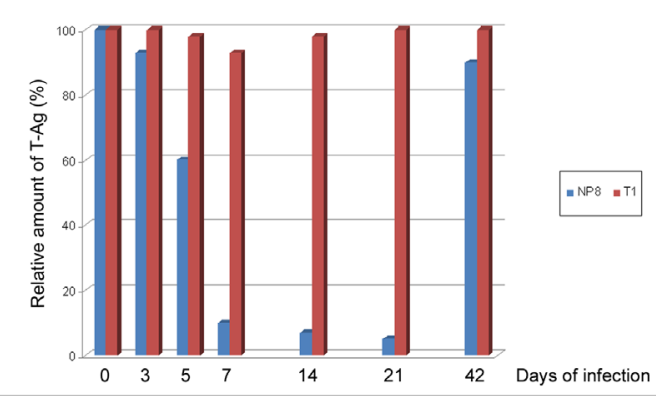

Figure 6: Specific elimination of T-Ag ${ }_{\mathrm{NP}}$ expressing mammary tumor cells after LCMV infection. A. NP8 mice (upper panels) or T1 mice (lower panels) bearing mammary tumors (diameter about $1.0 \mathrm{~cm}$ ) were infected with $10^{5} \mathrm{PFU}$ of LCMV and tumors of mammary glands were prepared and stained for T-Ag at days 0, 3, 5, 7, 14 (not shown), 21, and 42 (not shown). B. Comparison of T-Ag expression (different magnifications) in tumors of NP8 (upper panels) and T1 mice (lower panels) 21 days after infection with LCMV. C. Demonstration of the transient elimination of tumor cells in NP8 mice (blue columns) and T1 mice (red columns) after virus infection by the loss of tumor-derived T-Ag (visual calculation of different fields within the stained samples).

\section{A) Western Blot}

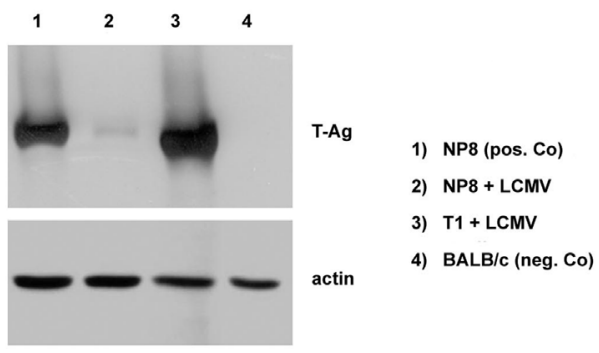

\section{B) ELISA}

$$
\begin{aligned}
& \begin{array}{lllll}
1 & 2 & 3 & 4 & \text { Sample Nr. }
\end{array} \\
& 5.180 .11 \quad 4.15<\mathrm{ng} \mathrm{T}-\mathrm{Ag} / \mu \mathrm{g} \text { protein }
\end{aligned}
$$

Figure 7: Quantitative comparison of T-Ag expression in tumors after infection with LCMV. Amounts of T-Ag were measured after infection with $10^{5}$ PFU NP8 (2) and T1 (3) mice in tumor lysates at day 7 pi; uninfected NP8 tumor (1), and BALB/c mice (4) served as positive and negative controls, respectively. Reduction of T-Ag levels in tumor lysates after LCMV infections of NP8 and T1 mice was examined in parallel by Western blotting A. or by ELISA B. 
cells could be achieved repeatedly by consecutive LCMV infections, but tumors always grew back (data not shown).

\section{Analysis of spontaneous NP-epitope specific $\mathrm{CD8}^{+} \mathrm{T}$-cell responses in $\mathrm{WAP}_{-} \mathrm{T}_{\mathrm{NP}}$ mice}

$\mathrm{T}-\mathrm{Ag}$ in $\mathrm{T} 1$ and $\mathrm{T}-\mathrm{Ag}_{\mathrm{NP}}$ in NP8 mice are encoded by their respective WAP-driven transgenes and thus have to be considered "self"-proteins. Usually, mammals establish tolerance or anergy against self-proteins during their development. In line, T1 and NP8 mice both lacked detectable T-Ag specific immunity. In contrast, we observed a strong LCMV NP-epitope specific immunity in NP8 mice. This may be suggestive for differential tolerance versus immunogenicity of specific antigenic determinants. We thus considered the possibility that WAP- $\mathrm{T}_{\mathrm{NP}}$ mice a priori were not tolerant against the NPepitope in $\mathrm{T}-\mathrm{Ag}_{\mathrm{NP}}$. Therefore, we addressed the question, whether in WAP- $\mathrm{T}_{\mathrm{NP}}$ mice NP-epitope specific immune responses are detectable without exogenous immunization.

Treatment of WAP-T ${ }_{\mathrm{NP}}$ NP6 mice with anti-CD8 antibodies or sub-lethal irradiation leads to an increase of $\mathrm{T}-\mathrm{Ag}_{\mathrm{NP}}$ expressing mammary epithelial cells after involution

In $\mathrm{WAP}_{\mathrm{NP}}$ mice, the first appearance of $\mathrm{T}-\mathrm{Ag}_{\mathrm{NP}}$ positive cells is late in pregnancy and then during lactation in mammary glands of induced mice. If $\mathrm{WAP}-\mathrm{T}_{\mathrm{NP}}$ mice were not tolerant against the NP-epitope, NP-specific CD8 ${ }^{+}$ T-cells should be generated latest during lactation phase, and in consequence should lead to an elimination of $\mathrm{T}-\mathrm{Ag}_{\mathrm{NP}}$ expressing cells later on, i.e. in involuted glands. If this were the case, elimination of $\mathrm{CD} 8^{+} \mathrm{T}$-cells in $\mathrm{WAP}-\mathrm{T}_{\mathrm{NP}}$ mice after birth of offspring should enhance the frequency of $\mathrm{T}-\mathrm{Ag}_{\mathrm{NP}}$ positive cells in involuted glands. To test this hypothesis we used NP6 mice (for a detailed description of NP6 mice see Materials and methods), as $\mathrm{T}-\mathrm{Ag}_{\mathrm{NP}}$ expressing cells are scarce (i.e. in most cases not detectable at all) in involuted mammary glands of NP6 mice (Fig. 8A, left). Thus an increase in $\mathrm{T}-\mathrm{Ag}_{\mathrm{NP}}$ positive cells after immunesuppressive treatment would be much easier to detect than in NP8 mice in which the majority of ducts contain T- $\mathrm{Ag}_{\mathrm{NP}}$ positive cells. We treated NP6 mice at day $1 \mathrm{pp}$ with antiCD8 antibodies and checked at day 20 post weaning (pw) for changes in the amount of $\mathrm{T}-\mathrm{Ag}_{\mathrm{NP}}$ expressing cells in involuted mammary glands. Fig. 8A, right panel, shows that already a single dose of anti-CD8 antibodies significantly increased the number of $\mathrm{T}-\mathrm{Ag}_{\mathrm{NP}}$ positive cells. Continuous treatment by repeated injections of anti-CD8 antibodies, beginning at birth and then every 20 days, led to an even stronger increase in $\mathrm{T}-\mathrm{Ag}_{\mathrm{NP}}$ positive ducts in involuted glands (Fig. 8B, left), when observed 100 days pp. Sublethal irradiations of NP6 mice, i.e. a more generalized immune-suppression, performed in parallel at the same time intervals led to a similar increase in $\mathrm{T}-\mathrm{Ag}_{\mathrm{NP}}$ positive cells (Fig. 8, right). The data suggest that $\mathrm{WAP}_{\mathrm{N}} \mathrm{T}_{\mathrm{NP}}$ mice mount

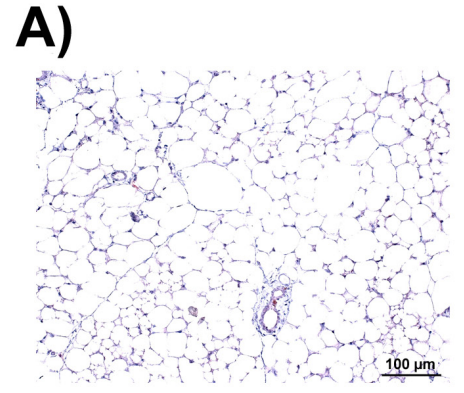

untreated control

\section{B)}

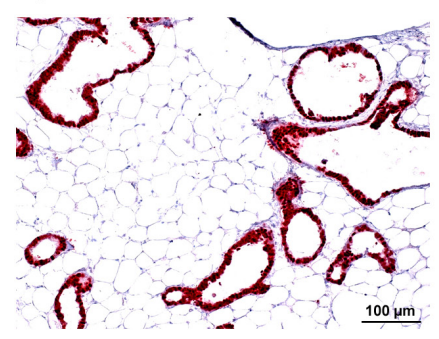

$5 \times$ anti CD8

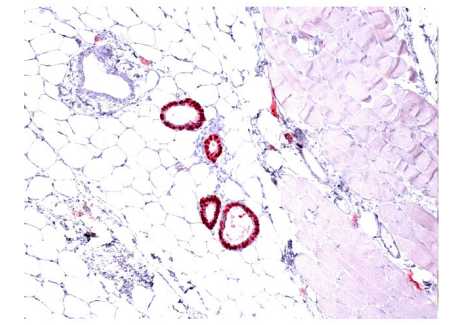

$1 \mathrm{x}$ anti CD8

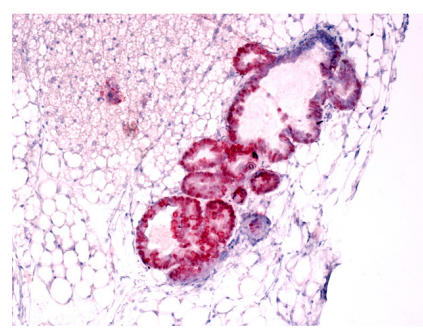

$5 \times 4$ Gy

Figure 8: Immune depletion enhances the amount of T-Ag expressing mammary cells in NP6 mice after involution. A. Increase after a single treatment with $400 \mu \mathrm{g}$ of anti CD8 antibodies at day $1 \mathrm{pp}$ and analysis at day $20 \mathrm{pw}$ (right) in comparison to an untreated NP6 mouse (left). B. Increase of T-Ag expressing mammary epithelial cells in involuted NP6 mice by repeated treatments with anti CD8 antibodies (left) or sub-lethal irradiation (right) analyzed 20 days after the last handling. 
a spontaneous immune response against the NP-epitope and thus are not tolerant against the NP-epitope in $\mathrm{T}-\mathrm{Ag}_{\mathrm{NP}}$.

\section{NP8 tumor mice contain $\mathrm{CD8}^{+} \mathrm{T}$-cells against the NP- epitope}

We next asked, whether we can detect NP-epitope specific $\mathrm{CD} 8^{+} \mathrm{T}$-cells also in NP8 tumor mice. Adoptive transfer of splenocytes from NP8 tumor mice into LCMV infected $\mathrm{BALB} / \mathrm{c}$ mice and the possible reduction in virus titer 7 days later served as read-out system. As positive control we used splenocytes from LCMV infected BALB/c mice, harvested 7 days after infection with LCMV (Fig. 9A). While the titer of LCMV in untreated control mice remained at a mean of $3 \times 10^{6} \mathrm{PFU} / \mathrm{g}$ of tissue (Fig. 9A, lane 1), transfer of splenocytes from LCMV infected BALB/c mice eliminated LCMV from the spleen of infected mice below the level of detectability (Fig. 9A, lane 2). Transfer of splenocytes from NP8 tumor mice reproducibly reduced virus load by about one $\log _{10}$ (Fig 9A, lane 3), i.e. by about $90 \%$, indicative for a significant, though comparatively weak anti-NP-epitope specific CTL activity in these mice. We conclude that NP8 tumor mice contain $\mathrm{CD} 8^{+} \mathrm{T}$-cells against the NP-epitope which elicit a weak, but measurable anti-NP-epitope specific CTL activity.

\section{Splenocytes in NP8 tumor mice contain a large population of PD1 expressing cells}

To get more information on the immune status of NP8 tumor mice, we compared the composition of splenocytes from wtBALB/c and NP8 tumor mice. Fig. 9B shows an enhanced frequency of $\mathrm{CD} 4^{+} \mathrm{T}$ cells in NP8 tumor compared to wtBALB/c mice, while the fraction of $\mathrm{CD}^{+} \mathrm{T}$ cells is rather similar in wtBALB/c and in NP8 tumor mice. Prominent increases in NP8 tumor mice were found in the fractions of $\mathrm{CD} 25^{+}$cells, which could explain the enhanced frequency of $\mathrm{CD}^{+}$ $\mathrm{T}$ cells in NP8 tumor compared to wtBALB/c mice, as $\mathrm{CD} 25^{+}$cells also include $\mathrm{CD} 4^{+}$regulatory T-cells. Furthermore, an enhancement was observed in NK cells and in $\mathrm{CD} 107^{+}$positive cells, indicative for the presence of activated $\mathrm{NK}$ and $\mathrm{CD} 8^{+}$T-cells. The most striking observation, however, was the strong increase in the frequency of cells expressing the programmed death-1 (PD1) molecule. PD1 is part of a pathway negatively regulating immune responses and can be expressed on activated $\mathrm{T}$ and $\mathrm{B}$ cells, on mesenchymal stem cells, but is highly expressed on exhausted $\mathrm{CD} 8^{+} \mathrm{T}$ cells [17], thereby impeding their activity. To determine the fraction of $\mathrm{PD} 1^{+}$ positive cells within the $\mathrm{CD} 8^{+} \mathrm{T}$-cell compartment, we first sorted splenocytes for $\mathrm{CD} 8^{+} \mathrm{T}$-cells. Sorted CD8 ${ }^{+}$ T-cells then were stained with anti-PD1 antibodies and again analyzed by FACS (Fig. 9C), which revealed a strong increase of $\mathrm{PD}^{+}$cells within the pre-selected CD8 ${ }^{+}$compartment in NP8 tumor mice (23\% and 50\%) in comparison to wtBALB/c mice ( $9 \%$ and $17 \%$ ).
Anti-PD1 treatment functionally reactivates exhausted NP-epitope specific T-cells in NP8 tumor mice

To test, whether the activity of NP-epitope specific $\mathrm{CD} 8^{+} \mathrm{T}$ cells in NP8 tumor mice indeed is impaired by expression of PD1, NP8 tumor mice were treated once with $(50 \mu \mathrm{g})$ anti-PD1 antibodies. At day 7 after treatment, splenocytes were harvested and used for adoptive transfer into LCMV infected BALB/c mice. Fig. 9A, lane 4 demonstrates a significant reduction of the virus titer in these mice. As in BALB/c mice NP-epitope specific CTLs are the only immune cells responsible for LCMV elimination, we conclude that anti-PD1 treatment of splenocytes from NP8 tumor mice leads to a re-activation of $\mathrm{CD} 8^{+} \mathrm{T}$-cells, whose activity in tumor mice is compromised by expression of PD1.

The data demonstrate that NP8 tumor mice contain weakly reactive NP-epitope specific $\mathrm{CD}^{+} \mathrm{T}$-cells; the majority of those, however, is exhausted by expression of PD1, but can be at least partially reactivated by treatment with anti-PD1 antibodies.

\section{DISCUSSION}

Immune-therapy of cancers holds great promise, but up to now tumor-induced mechanisms that lead to immune-evasion pose major barriers to its successful application [18]. Analysis of the immune status of a given tumor entity and identification of the obstructed immune checkpoints thus are crucial issues for the development of immune-therapeutic anti-cancer strategies. Due to the limited possibilities for analyzing the respective parameters in humans, suitable animal models should be of great value. While a large number of studies has shown that it is possible to protect mice against tumor transplants by pre-immunization with the respective tumor antigens (protective immunization), very few studies so far have examined, whether and how the growth of naturally arising tumors can be controlled by inducing a tumor antigen specific immune response (curative immunization).

In this study we focused on epitope-specific $\mathrm{CD} 8^{+}$ T-cell responses against WAP-T mammary epithelial cells expressing a chimeric SV40 $\mathrm{T}-\mathrm{Ag}$, carrying the $\mathrm{H}-2^{\mathrm{d}}$ restricted NP-epitope of LCMV $\left(\mathrm{T}-\mathrm{Ag}_{\mathrm{NP}}\right)$. While the CTL-immune-response of BALB/c mice against T-Ag specific $\mathrm{H}-2^{\mathrm{d}}$ restricted T-cell epitopes is very weak, though measurable [10], the LCMV NP-epitope is the strong, singular immune-dominant $\mathrm{CD} 8^{+} \mathrm{T}$-cell epitope in BALB/c mice $[11,13,19]$. Our rationale was that this immune-dominant epitope, inserted into a transformationirrelevant region of SV40 T-Ag, might allow the induction of a strong $\mathrm{CD}^{+}$T-cell response in $\mathrm{WAP}^{-} \mathrm{T}_{\mathrm{NP}}$ mice after immunization with LCMV. Taking advantage of immune-dominant epitopes in analyzing epitope-specific CTL-responses against endogenously arising tumors is not a new approach. Speiser et al. [20] and Schell et al. [21] already demonstrated that it is possible to override 
A)

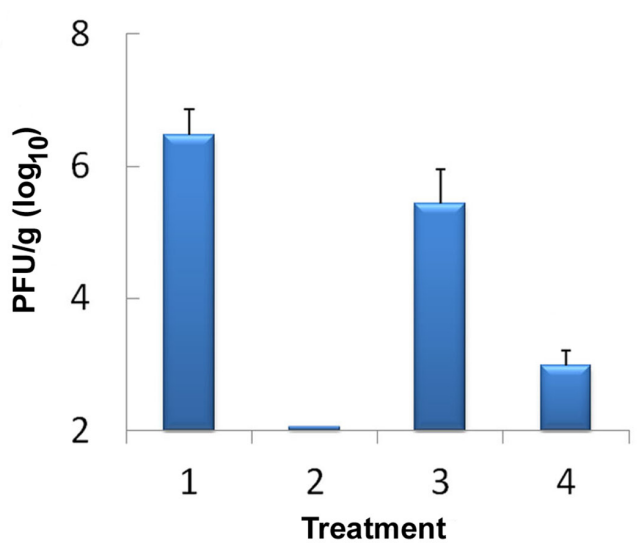

B)

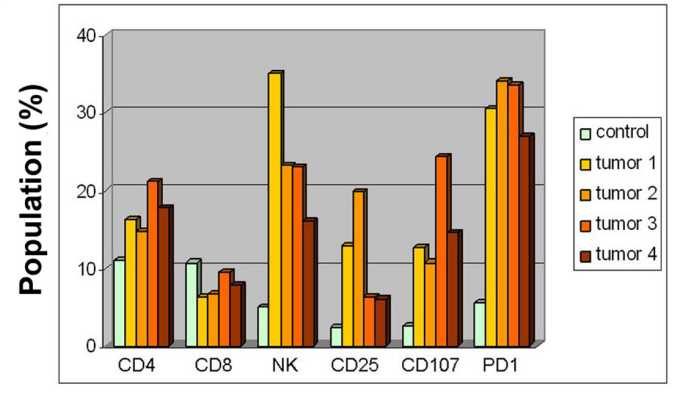

Splenocytes

\section{C)}
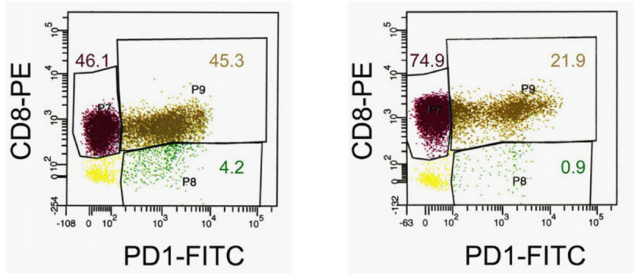

$\frac{\infty}{2}$
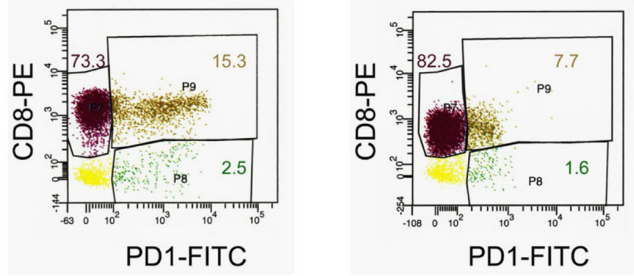

$\frac{0}{\frac{1}{m}}$

Figure 9: Detection of NP-epitope specific CTLs in NP8 tumor mice. A. Adoptive transfer of immune cells into LCMV-infected $\mathrm{BALB} / \mathrm{c}$ mice. CTLs were obtained from BALB/c mice infected with LCMV (2, positive control), from NP8 tumor mice (3), from NP8 tumor mice and applied together with anti-PD1 antibodies (4); untreated BALB/c mice were introduced as negative controls (1); the means and standard errors of 5 mice are shown. B. Examination by FACS of splenocytes from wtBALB/c and NP8 tumor mice. Splenocytes from one BALB/c (control) and four NP8 tumor mice (tumors 1-4) were isolated and studied by FACS. C. Splenocytes from two NP8 tumor mice and two BALB/c control mice were sorted with anti-CD8 antibodies. Then these pre-selected cells were stained with anti-PD1 antibodies for a final analysis via FACS. The results revealed an increase of CD $8^{+} \mathrm{PD} 1^{+}$cells (brown) of 45.3 and $21.9 \%$ versus $\mathrm{CD} 8^{+} \mathrm{PD} 1^{-}$ cells (violet) of 46.1 and $74.9 \%$ in NP8 tumor mice in comparison to $\mathrm{CD} 8{ }^{+} \mathrm{PD}^{+}$cells (brown) of 15.3 and $7.7 \%$ versus $\mathrm{CD}^{+} \mathrm{PD}^{-}$cells (violet) of 73.3 and $82.5 \%$ in wtBALB/c mice; the minor fractions presented here were CD $8{ }^{-} \mathrm{PD} 1^{+}$cells (green) between 0.9 and $4.2 \%$ and $\mathrm{CD}^{-} \mathrm{PD}^{-}$cells or cellular debris (yellow) between 2.3 and $8.9 \%$ in all mice, respectively. 
epitope-specific tolerance and mount a CTL-specific antitumor immune-response by immunization with a strong immunogen expressing the respective CTL-epitope.

To analyze NP-epitope specific T-cell responses in NP8 mice we used two different approaches, infection of the mice with LCMV or NP-epitope expressing VV recombinants, and transfer of splenocytes from LCMV infected wtBALB/c mice. Both approaches unequivocally demonstrated that NP-epitope specific $\mathrm{CD}^{+} \mathrm{T}$-cells specifically eliminate $\mathrm{T}-\mathrm{Ag}_{\mathrm{NP}}$ expressing cells in NP8 mice both prior to as well as after tumor development. Elimination of tumor cells after LCMV infection of NP8 tumor mice was almost complete, as judged by immunehistochemistry and by measuring the $\mathrm{T}-\mathrm{Ag}_{\mathrm{NP}}$ content in tumor lysates. However, this elimination was only transient, as starting with day 21 after LCMV treatment tumors recurred. Even repeated immunizations with LCMV did not succeed to achieve long term immunity. This finding was similar as in RIP(Tag2 $\times$ GP) mice [20], where immunization with LCMV also led to strong tumor reduction, but not to complete and long lasting elimination.

The stringent NP-epitope specificity of CTLs observed in NP8 mice after infection with LCMV or after adoptive transfer of splenocytes from LCMV infected BALB/c mice is based on several arguments: (1) the $\mathrm{NP}$-epitope contained within the chimeric $\mathrm{T}-\mathrm{Ag}_{\mathrm{NP}}$ protein is the only LCMV-specific epitope present in NP8 mice; (2) NP8 mice showed a virus dose-dependent reduction of the T-Ag load in the tissues of mammary glands (Fig. 4A); (3) specific elimination of T-Ag expressing cells was observed only by a vaccinia virus recombinant expressing the NP molecule of LCMV but not with recombinants expressing either the glycoprotein-precursor of LCMV or the T-Ag of SV40 (Fig. 4B and Supplementary Fig. 1); (4) reduction of T-Ag positive cells could be achieved by adoptive transfer of immune cells only when lymphocytes were used from BALB/c mice infected with LCMV or VV-YN4 (Fig. 5); (5) specific elimination of T-Ag expressing tumor cells was observed by LCMV infection of individual NP8 tumor mice but not T1 mice (Fig. 6).

The novel finding in our system was that induced as well as tumor bearing WAP- $\mathrm{T}_{\mathrm{NP}}$ mice showed an endogenous NP-epitope specific CTL-response, and thus that these mice were not tolerant against this epitope. This conclusion had been already suggested by our initial experiments demonstrating that NP8 mice were able to mount a very strong, NP-epitope specific immune response after LCMV infection (Table I and Fig. 2). This finding was somewhat surprising, as the chimeric $\mathrm{T}-\mathrm{Ag}_{\mathrm{NP}}$ is expressed from a transgene and thus should be treated immunologically as a "self"-protein. We do not have a conclusive explanation, especially since in the studies by Speiser et al. [20] and Schell et al. [21] cited above non-immunized mice were tolerant against the analyzed immune-dominant CTL-epitopes. However, an important difference between their animal models and ours is that in their mice the transgenes are continuously expressed starting with organ development, while $\mathrm{T}-\mathrm{Ag}_{\mathrm{NP}}$ in WAP$\mathrm{T}_{\mathrm{NP}}$ mice is first expressed very late in pregnancy and then strongly during lactation and later on in tumors. In this respect our model more closely mimics naturally occurring tumors in humans, where tumor neo-antigens are also presented only in cancer.

The NP-epitope specific immune status of WAP- $\mathrm{T}_{\mathrm{NP}}$ mice may bear similarity to the antigen specific immune status in chronic infection $[22,23]$, where the $\mathrm{CD} 8^{+}$ T-cell response is down-regulated, but not completely abolished by surface receptors of negative regulatory pathways, e.g. PD1. In line with this idea we found that $\mathrm{WAP}_{\mathrm{NP}}$ mice are able to mount a spontaneous $\mathrm{CD}^{+} \mathrm{T}$-cell response against the NP-epitope in $\mathrm{T}-\mathrm{Ag}_{\mathrm{NP}}$. Treatment of NP6 mice after birth of offspring with anti-CD8 antibodies or sub-lethal irradiation provided a first hint for the existence of reactive, NP-specific $\mathrm{CD} 8^{+}$ T-cells, as such treatment led to a strong increase in $\mathrm{T}-\mathrm{Ag}_{\mathrm{NP}}$ positive cells after involution. Furthermore, NP8 tumor mice contained reactive NP-epitope-specific $\mathrm{CD} 8^{+}$ T-cells, as splenocytes from such mice after adoptive transfer weakly, though measurably reduced the virus load in LCMV infected wtBALB/c mice. This inadequate endogenous immune response suggested that NP-specific CD8 ${ }^{+}$T-cells in NP8 tumor mice were in a weakly reactive state, thereby explaining why they were not able to prevent tumor outgrowth. In support, FACS analyses of splenocytes from NP8 tumor mice revealed that a large fraction of the immune cells, specifically of $\mathrm{CD} 8^{+} \mathrm{T}$-cells, expressed PD1, a commonly accepted marker for T-cell exhaustion $[17,24]$. However, as recently demonstrated by Utzschneider et al. [23] in chronic LCMV infection, PD1 mediated exhaustion of $\mathrm{CD}^{+}$T-cells is not absolute and could mark a specific state of $\mathrm{CD} 8^{+} \mathrm{T}$-cell differentiation in a given immunological setting (e.g. in chronic infection) rather than an irreversible pathway of $\mathrm{CD}^{+} \mathrm{T}$-cell elimination. This view is supported by our findings that already adoptive transfer of untreated splenocytes from $\mathrm{WAP}_{\mathrm{NP}}$ tumor mice into $\mathrm{LCMV}$ infected wtBALB/c mice led to a slight reduction in LCMV titer in BALB/c mice (Fig. 9). Adoptive transfer of anti-PD1 treated splenocytes from $\mathrm{WAP}_{\mathrm{NP}}$ tumor mice into LCMV infected $\mathrm{BALB} / \mathrm{c}$ mice then led to a significant re-activation of NP-epitope specific cytotoxic $\mathrm{CD} 8^{+} \mathrm{T}$-cells, underscoring the role of PD1 expression in the control of CTL activity.

We interpret our data as to indicate that transgene expressing NP8 mice contain NP-epitope specific CTLs, which, however, are only partially reactive due to expression of PD1, and thus are not sufficient to control tumor growth. In analogy, we consider it likely that the only transient elimination of NP8 tumor cells in NP8 tumor mice after LCMV infection also reflects PD1 mediated exhaustion of NP-epitope specific CD8 ${ }^{+} \mathrm{T}$-cells generated during infection, i.e. the restoration of the 
compromised immune-status in tumor mice by repeated antigen stimulation. Very recently, anti-PD1 treatment of NP8 tumor mice has evolved as a promising approach for re-activation of the spontaneous immune response against tumors [25]. However, such a treatment must be coupled with measures that effectively prevent the re-establishment of the PD1-mediated compromised immune-status.

The WAP- $\mathrm{T}_{\mathrm{NP}}$ model described in this study to our best knowledge is unique insofar that these mice are not tolerant to a transgene-encoded tumor antigen. It thus may serve as a model for human tumors, as it is well known that human tumors can mount specific CTL-responses against their tumor antigens. The probably best known tumor entity in this respect are melanomas, and boosting their cellular immune response by various approaches has been used in immune therapy, though previously with limited success [26], if applied without measures restoring compromised immune checkpoints [25]. It is most likely that many human tumors develop a spontaneous cellular immune response against tumor antigens, which prospectively could be used for immune therapy. Thus the WAP- $\mathrm{T}_{\mathrm{NP}}$ model might be helpful in deciphering the parameters that will finally allow successful curative immunization strategies.

\section{MATERIALS AND METHODS}

\section{Mice}

For our analyses, we selected the WAP-T mouse line $\mathrm{T} 1$ as an NP-epitope negative control, and two WAP- $\mathrm{T}_{\mathrm{NP}}$ mouse lines, WAP-T-NP6 (NP6) and WAP-T-NP8 (NP8), respectively [5]. If not stated otherwise, generally five mice per group were used in each experiment. NP6 and NP8 mice differ in their characteristics of tumor formation: NP8 mice are very similar to T1 mice [2], strongly expressing the SV40 T-Ag in about 50\% (NP8) to about $90 \%$ (T1) of epithelial cells of lactating mammary glands (Fig. 1B). The majority of T-Ag positive cells are eliminated during involution, but proliferation of T-Ag expressing progenitor cells that survived involution soon leads to the appearance of T-Ag positive ducts. Consequently, virtually all terminal end buds in T1 and NP8 mice develop intraepithelial neoplasia (MIN) within 90-120 days post weaning (pw) $[6,27]$. Within the same time frame (6-8 months) T1 and NP8 mice develop between 2 to maximally 6 (average 3 ) invasive mammary carcinomas. In contrast, in induced NP6 mice only very few T-Ag expressing cells (about 2\%) are found in ducts of lactating mammary glands (Fig. 1B). Correspondingly, only very few $\mathrm{T}-\mathrm{Ag}_{\mathrm{NP}}$ positive cells can be detected in mammary glands of NP6 mice after involution, and only a few MIN, but no outgrowth to invasive carcinomas are observed. However, after a two-fold induction 90\% of NP6 mice also develop invasive carcinomas, which arise significantly later than in T1 or NP8 mice. No metastases were found in two-fold induced NP6 tumor mice (unpublished data).

$\mathrm{BALB} / \mathrm{c}$ and transgenic mice were held under specific pathogen-free conditions, and the generation of WAP-T or WAP-T $\mathrm{T}_{\mathrm{NP}}$ mice was described in detail elsewhere [5]. The WAP promoter is hormonally and developmentally regulated by lactotrophic hormones (e.g. estrogen, prolactin, hydrocortison, insulin) [28]. Thus expression of the transgene can be induced by mating and is directed to epithelial cells of ducts of the differentiating and lactating mammary glands. Before adoptive transfer of immune cells, acceptor mice were $\gamma$-irradiated sub-lethally with a radiation dose of 4 Gray by the Cs-137 source (2,500-3,000 Curie) of a LISA I apparatus (Conservatome). Similarly, in some cases NP6 mice were dealt with sub-lethal irradiations or were alternatively treated ip with $400 \mu \mathrm{g}$ of monoclonal antibodies (mAbs) against anti-CD8 [29, 30]. For the specific removal of exhausted $\mathrm{T}$ cells mice were treated with $50 \mu \mathrm{g}$ anti-PD1 mAbs (eBioscience).

\section{Virus and cells}

The plaque-purified WE strain of LCMV [31], SV40 [32], and VV as well as VV recombinants [13, 21] were propagated and titrated in mouse NCTC clone $929 \mathrm{~L}$ cells using minimal essential medium supplemented with nonessential amino acids and 5\% heated calf serum at $37^{\circ} \mathrm{C}$ [33]; the virus was quantitatively expressed as numbers of plaque-forming units (PFU) [34]. Mice were, if not stated otherwise, infected with $10^{5} \mathrm{PFU}$ of virus intravenously (iv), ip, sc, or into the foot-pad according to described procedures [30]. Donor $\mathrm{BALB} / \mathrm{c}$ mice were infected with $10^{2}$ PFU of virus before transfer of splenocytes into acceptor mice.

\section{Immune histochemistry}

Histopathology and analysis of transgene expression were essentially as already described [5]. In brief, mouse mammary tissue specimens were fixed with $4 \%$ formaldehyde containing $1 \%$ acetic acid and embedded in paraffin. Deparaffinated sections were stained with hematoxylin and eosin. Immunostaining of SV40 large T-antigen was performed on paraffin sections using a triple-step immunoenzymatic method. Deparaffinated sections were reacted before antibody incubation with a commercial 'target unmasking fluid' (Dianova) in a microwave oven. Subsequently, sections were incubated overnight at $48^{\circ} \mathrm{C}$ with a $1: 10,000$ dilution of the polyclonal rabbit antiserum R15 against T-Ag [35]. Specifically bound primary antibody was detected using biotinylated anti-rabbit $\mathrm{IgG}$ and phosphatase-conjugated streptavidin from a commercial kit (Super Sensitive Detection System, Biogenex). Phosphatase enzyme activity was revealed with naphthol 
AS-BI phosphate in combination with hexazotized new fuchsine (Merck). Naïve rabbit serum served as control. Sections were slightly counterstained with hemalum. All photographs were taken by the Zeiss Axioplan2 imaging microscopic equipment with the camera ProgRes C12plus of Jenoptic using the Software ProgRes CapturePro 2.9.0.1.

\section{FACS}

Analysis of splenocytes were performed usually with $5 \times 10^{5}$ cells per staining. Cells were washed and resuspended in $100 \mu \mathrm{l}$ PBS buffer; thereafter $1 \mu \mathrm{l}$ of FITC- or PE-stained antibodies (BD Biosciences) were added according to the manufacturer's instructions. For the examination of the relevant cellular populations the following mAbs, all obtained from BD Biosciences, were used: rat anti-mouse CD8 as well as CD4, mouse anti-mouse NK1.1, rat anti-mouse CD25, rat anti-mouse CD107a, and hamster anti-mouse PD1 and incubated in the dark for $2 \mathrm{~h}$. In order to inhibit unspecific binding rat anti-mouse CD16/CD32 was included to each arrangement as Fc block. Appropriate rat anti-mouse IgG1, IgG2a, and $\operatorname{IgG} 2 \mathrm{~b}$ were introduced as isotype controls. Cells were resuspended in $500 \mu \mathrm{l}$ FACS buffer $(0.5 \%$ FCS, $100 \mu \mathrm{M}$ EDTA in PBS) and analyzed in a FACSAria I cell sorter (Becton Dickinson) with BD FACS Diva 5.1.3 software. For analysis of the fraction of CTLs expressing the PD1 protein $\mathrm{CD} 8^{+}$cells were first sorted after incubation of splenocytes with anti-mouse CD8 antibodies for $2 \mathrm{~h}$ in the dark and then examined by FACS using the anti-mouse PD1 antibodies described above.

\section{Detection of LCMV-specific cytotoxic T-cells}

The activity of CTLs was quantified by standard $4 \mathrm{~h}$ ${ }^{51} \mathrm{Cr}$-release assays according to Brunner and coworkers [36] with the modification that the incubation time for the target cells was diminished to $4 \mathrm{~h}$ at $37^{\circ} \mathrm{C}$ as already mentioned [30]. The specificity of the immune reaction within the BALB/c background was verified by the LCMV NP pentamer haplotype with peptide sequence H-2Ld / RPQASGVYM. The quantity of discharged radioactive label was measured with a $\gamma$-ray scintillation counter (Berthold, Packard) and the specific release was calculated with the formula $[100 \times(a-b) /(c-b)]$ - $[100 \times(d-b) /(c-b)]$, where $a=$ counts of antigen-positive target cells co-incubated with immune lymphoid cells, $\mathrm{d}=$ counts of non-infected target cells in the presence of immune lymphoid cells, $\mathrm{b}=$ counts of target cells only, and $\mathrm{c}=$ counts of lysed target cells.

\section{Protein measurement and detection of T-Ag in ELISA and western blotting}

The procedures were already described in more details [37]. Briefly, the protein content was calculated using the Bio-Rad protein assay with the Bradford Reagent [38]. For the determination of the amounts of T-Ag an ELISA was carried out, where aliquots of the samples were adsorbed onto MaxiSorp Immunoplates (Nunc) for $2 \mathrm{~h}$ at room temperature. The detection of viral antigen was performed with the rabbit anti T-Ag antiserum R15 [35] followed by horseradish peroxidase-labeled goat anti rabbit immunoglobulins (Medac). The presence of T-Ag was also visualized after electrophoretic separation of whole cell lysates in 5 to $20 \%$ polyacrylamide gradient gels [39] and blotting onto PVDF membranes (Bio-Rad), which were incubated with anti-T-Ag antiserum R15 diluted 1:1000.

\section{ACKNOWLEDGMENTS}

We thank Dr. Frauke Krepulat for her advice on the biology of WAP-T and WAP-T ${ }_{\mathrm{NP}}$ mice, Annette Preuß for reliable work in the animal facility, and Gabriele Warnecke for expert technical assistance. We also thank Arne Düsedau for FACS support, Gundula PilnitzStolze for competent technical assistance and the staff of the HPI animal quarters for their help. Special thanks go to Dr. R.M. Zinkernagel (Institute of Pathology, University Hospital, Zurich, Switzerland) and Dr. T.D. Schell (Department of Microbiology and Immunology, Pennsylvania State University College of Medicine, Hershey, USA), who provided us with the recombinant vaccinia viruses VV-YN4, VV-G2 and VV-941T, respectively.

This manuscript is dedicated to the memory of our late colleague and mentor Prof. Dr. Fritz LehmannGrube, whose enthusiasm inspired our interest in tumor immunology.

\section{GRANT SUPPORT}

This study was supported by funds from the Heinrich-Pette-Institute, the Hamburger Krebsgesellschaft, and the Fonds der Chemischen Industrie. The HeinrichPette-Institute is financially supported by the Freie und Hansestadt Hamburg and the Bundesministerium für Gesundheit.

\section{Abbreviations}

Co, control; CTL, cytotoxic T lymphocyte; HE, hematoxylin and eosin; ip, intraperitoneal; iv, intravenous; LCMV, lymphocytic choriomeningitis virus; $\mathrm{mAb}$, monoclonal antibody; MHC, major histocompatibility comples; MIN, mammary intraepithelial neoplasia; mutp53, mutant p53; NK, natural killer cell; NP nucleoprotein of LCMV; NP6, WAP-T-NP6 mouse; NP8, WAP-T-NP8 mouse; PD1, programmed death-1 protein; PD-L1, ligand of PD1; PFU, plaque-forming units; pi, post infectionem; pp, postpartum; pw, post weaning; sc, subcutaneous; SV40, Simian virus 40; T1, WAP-T1 
mouse; T-Ag, T-antigen of SV40; $\mathrm{T}-\mathrm{Ag}_{\mathrm{NP}}$, chimeric $\mathrm{T}-\mathrm{Ag} /$ NP protein; VV, vaccinia virus; VV-941T, VV containing SV40 T-Ag; VV-G2, VV containing LCMV glycoprotein precursor; VV-YN4, VV containing LCMV nucleoprotein; WAP, whey acidic protein; wt, wild type.

\section{CONFLICTS OF INTEREST}

The authors declare no potential conflicts of interest.

\section{REFERENCES}

1. Jemal A, Bray F, Center MM, Ferlay J, Ward E, Forman D. Global cancer statistics. CA Cancer J Clin. 2011; 61:69-90.

2. Jannasch K, Wegwitz F, Lenfert E, Maenz C, Deppert W, Alves F. Chemotherapy of WAP-T mouse mammary carcinomas aggravates tumor phenotype and enhances tumor cell dissemination. Int J Cancer. 2014; 137:25-36.

3. Heinlein C, Krepulat F, Löhler J, Speidel D, Deppert W, Tolstonog GV. Mutant p53(R270H) gain of function phenotype in a mouse model for oncogene-induced mammary carcinogenesis. Int J Cancer. 2008; 122:1701-1709.

4. Lenfert E, Maenz C, Heinlein C, Jannasch K, Schumacher U, Pantel K, Tolstonog GV, Deppert W, Wegwitz F. Mutant p53 promotes epithelial-mesenchymal plasticity and enhances metastasis in mammary carcinomas of WAP-T mice. Int J Cancer. 2014; 136:E521-533.

5. Schulze-Garg C, Löhler J, Gocht A, Deppert W. A transgenic mouse model for the ductal carcinoma in situ (DCIS) of the mammary gland. Oncogene. 2000; 19:1028-1037.

6. Otto B, Gruner K, Heinlein C, Wegwitz F, Nollau P, Ylstra B, Pantel K, Schumacher U, Baumbusch LO, MartinSubero JI, Siebert R, Wagener C, Streichert T, Deppert W, Tolstonog GV. Low-grade and high-grade mammary carcinomas in WAP-T transgenic mice are independent entities distinguished by met expression. Int J Cancer. 2012; 132:1300-1310.

7. Otto B, Streichert T, Wegwitz F, Gevensleben H, Klatschke K, Wagener C, Deppert W, Tolstonog GV. Transcription factors link mouse WAP-T mammary tumors with human breast cancer. Int J Cancer. 2012; 132:1311-1322.

8. Tevethia SS. Recognition of simian virus $40 \mathrm{~T}$ antigen by cytotoxic T lymphocytes. Mol Biol Med. 1990; 7:83-96.

9. Schirmbeck R, Zerrahn J, Kuhrober A, Deppert W, Reimann J. Immunization of mice with the N-terminal (1-272) fragment of simian virus 40 large $\mathrm{T}$ antigen (without adjuvants) specifically primes cytotoxic $\mathrm{T}$ lymphocytes. Eur J Immunol. 1993; 23:1528-1534.

10. Utermöhlen O, Schulze-Garg C, Warnecke G, Gugel R, Löhler J, Deppert W. Simian virus 40 large-T-antigenspecific rejection of mKSA tumor cells in BALB/c mice is critically dependent on both strictly tumor-associated, tumor-specific $\mathrm{CD} 8(+)$ cytotoxic $\mathrm{T}$ lymphocytes and CD4(+) T helper cells. J Virol. 2001; 75:10593-10602.
11. Lehmann-Grube F, Assmann U, Löliger C, Moskophidis D, Löhler J. Mechanism of recovery from acute virus infection. I. Role of T lymphocytes in the clearance of lymphocytic choriomeningitis virus from spleens of mice. J Immunol. 1985; 134:608-615.

12. Weidt G, Deppert W, Utermöhlen O, Heukeshoven J, Lehmann-Grube F. Emergence of virus escape mutants after immunization with epitope vaccine. J Virol. 1995; 69:7147-7151.

13. Hany M, Oehen S, Schulz M, Hengartner H, Mackett M, Bishop DH, Overton H, Zinkernagel RM. Anti-viral protection and prevention of lymphocytic choriomeningitis or of the local footpad swelling reaction in mice by immunization with vaccinia-recombinant virus expressing LCMV-WE nucleoprotein or glycoprotein. Eur J Immunol. 1989; 19:417-424.

14. Black PH, Rowe WP. SV-40 induced proliferation of tissue culture cells of rabbit, mouse, and porcine origin. Proc Soc Exp Biol Med. 1963; 114:721-727.

15. Gossmann J, Löhler J, Lehmann-Grube F. Entry of antivirally active $\mathrm{T}$ lymphocytes into the thymus of virus-infected mice. J Immunol. 1991; 146:293-297.

16. Cao W, Henry MD, Borrow P, Yamada H, Elder JH, Ravkov EV, Nichol ST, Compans RW, Campbell KP, Oldstone MB. Identification of alpha-dystroglycan as a receptor for lymphocytic choriomeningitis virus and lassa fever virus. Science. 1998; 282:2079-2081.

17. Keir ME, Butte MJ, Freeman GJ, Sharpe AH. PD-1 and its ligands in tolerance and immunity. Annu Rev Immunol. 2008.

18. Rabinovich GA, Gabrilovich D, Sotomayor EM. Immunosuppressive strategies that are mediated by tumor cells. Annu Rev Immunol. 2007; 25:267-296.

19. Zinkernagel RM, Doherty PC. Immunological surveillance against altered self components by sensitised $\mathrm{T}$ lymphocytes in lymphocytic choriomeningitis. Nature. 1974; 251:547-548.

20. Speiser DE, Miranda R, Zakarian A, Bachmann MF, McKall-Faienza K, Odermatt B, Hanahan D, Zinkernagel RM, Ohashi PS. Self antigens expressed by solid tumors do not efficiently stimulate naive or activated T cells: Implications for immunotherapy. J Exp Med. 1997; 186:645-653.

21. Schell TD, Mylin LM, Georgoff I, Teresky AK, Levine AJ, Tevethia SS. Cytotoxic T-lymphocyte epitope immunodominance in the control of choroid plexus tumors in simian virus 40 largeT antigen transgenic mice. J Virol. 1999; 73:5981-5993.

22. Virgin HW, Wherry EJ, Ahmed R. Redefining chronic viral infection. Cell. 2009; 138:30-50.

23. Utzschneider DT, Legat A, Fuertes Marraco SA, Carrie L, Luescher I, Speiser DE, Zehn D. T cells maintain an exhausted phenotype after antigen withdrawal and population reexpansion. Nat Immunol. 14:603-610. 
24. Speiser DE, Utzschneider DT, Oberle SG, Munz C, Romero P, Zehn D. T cell differentiation in chronic infection and cancer: Functional adaptation or exhaustion?. Nat Rev Immunol. 2013; 14:768-774.

25. Tarhini AA, Lin Y, Zahoor H, Shuai Y, Butterfield KH, Ringquist S, Gogas H, Sander C, Lee S, Agarwala SS, Kirwood JM. Pro-inflammatory cytokines predict relapsefree survival after one month of interferon- $\alpha$ but not observation in intermediate risk melanoma patients. Plos One. 2015; 10:1-13.

26. Andrews MC, Woods K, Cebon J, Behren A. Evolving role of tumor antigens for future melanoma therapies. Future Oncol. 2014; 10:1457-1468.

27. Kumar M, Witt B, Knippschild U, Koch S, Meena JK, Heinlein C, Weise JM, Krepulat F, Kuchenbauer F, Iben S, Rudolph KL, Deppert W, Gunes C. CEBP factors regulate telomerase reverse transcriptase promoter activity in whey acidic protein- $\mathrm{T}$ mice during mammary carcinogenesis. Int J Cancer. 2012; 132:2032-2043.

28. Burdon T, Sankaran L, Wall RJ, Spencer M, Hennighausen L. Expression of a whey acidic protein transgene during mammary development. Evidence for different mechanisms of regulation during pregnancy and lactation. J Biol Chem. 1991; 266:6909-6914.

29. Cobbold SP, Jayasuriya A, Nash A, Prospero TD, Waldmann H. Therapy with monoclonal antibodies by elimination of T-cell subsets in vivo. Nature. 1984; 312:548-551.

30. Moskophidis D, Fang L, Gossmann J, Drjupin R, Löhler J, Bruns M, Lehmann-Grube F. Virus- specific delayed-type hypersensitivity (DTH). Cells mediating lymphocytic choriomeningitis virus-specific DTH reaction in mice. J Immunol. 1990; 144:1926-1934.
31. Rivers TM, Scott TF. Meningitis in man caused by a filterable virus: II. Identification of the etiological agent. J Exp Med. 1936; 63:415-432.

32. Butel JS, Lednicky JA. Cell and molecular biology of simian virus 40: Implications for human infections and disease. J Natl Cancer Inst. 1999; 91:119-134.

33. Lockart RZ Jr., Eagle H. Requirements for growth of single human cells. Science. 1959; 129:252-254.

34. Bruns M, Gessner A, Lother H, Lehmann-Grube F. Host cell-dependent homologous interference in lymphocytic choriomeningitis virus infection. Virology. 1988; 166:133-139.

35. Deppert W, Pates R. Simian virus 40 specific proteins on surface of HeLa cells infected with adenovirus 2-SV40 hybrid virus Ad2+ND2. Nature. 1979; 277:322-324.

36. Brunner KT, Mauel J, Cerottini JC, Chapuis B. Quantitative assay of the lytic action of immune lymphoid cells on 51-Cr-labelled allogeneic target cells in vitro; inhibition by isoantibody and by drugs. Immunology. 1968; 14:181-196.

37. Maenz C, Loscher C, Iwanski A, Bruns M. Inhibition of duck hepatitis B virus infection of liver cells by combined treatment with viral e antigen and carbohydrates. J Gen Virol. 2008; 89:3016-3026.

38. Bradford MM. A rapid and sensitive method for the quantitation of microgram quantities of protein utilizing the principle of protein-dye binding. Anal Biochem. 1976; 72:248-254.

39. Laemmli UK. Cleavage of structural proteins during the assembly of the head of bacteriophage T4. Nature. 1970; 227:680-685. 